\title{
وضع معايير تصميم الخط العربي الرقمي تحقق الناحية الوظيفية \\ والجمالية وتصلح للعناوين في المبوعات "
}

إعلداد

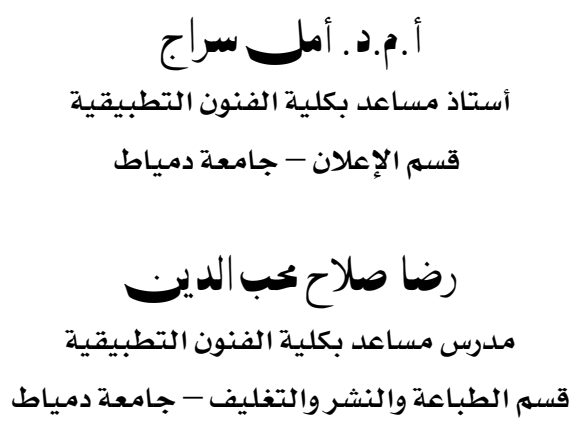

أ.م.ده. أملس سراج

أستاذ مساعد بكلية الفنون التطبيقية

قسم الإعلان - جامعة دمياط

رضا صلاح ححب الدير.

مدرس مساعد بكلية الفنون التطبيقية

قسم الطباعة والنشر والتغليف - جامعة دمياط

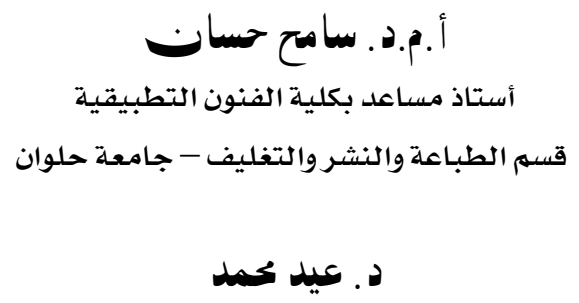
جامعة القاهرة

مجلة بحوث التربية النوعية ـ جامعة المنصورة

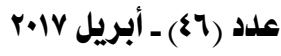




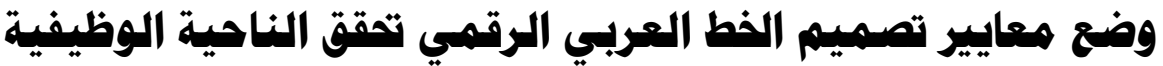 والجمبالية وتصاح للعناوين في الاطبـوعات
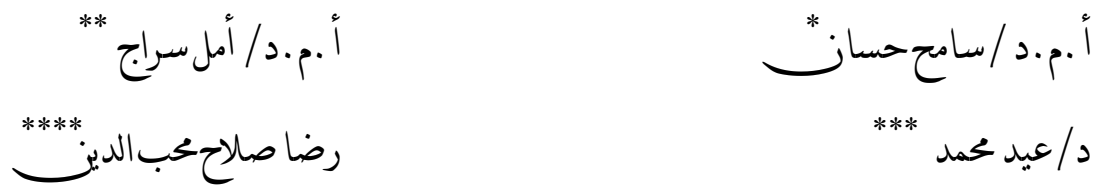

unil|

شهدت السنوات القليلة الماضيـة ظهور العديد من أشكال الحروف العربية التي استخدمت

يْ مجـال المطبوعات ، فقد رحبت المطبوعات الورقية بالجديد منها دون اهتمام ككايِّ بهدى ملائمتها - بحكم كثرتها واختلاف مستوى القائمـين عليها - وتحفظت صفحات الويب الصادرة عن المؤسسات الكبيرة يف استخدام الجديد منها ، واكتفت بـالأشكال المألوفة منها ، إلا أن كثير من تلك الحروف الجديدة لم يصل إلى مستوى الجودة و التميز الذي تحقق مـع الحروف اللاتينيـة ، ويعود هذا لأسباب عدة ، تأتى يخ مقدمتها تكوين الحرف العري نفسله ، فاختلاف شكل الحرف باختلاف موضعه ، وتغير رسمه حسب ما يجاوره من الحروف الأخرى ، هناك مشكلة كبيرة تنتج من التنوع ، وف الشديل يُ الهيئة العامـة أو الحدود المحيطة بالحرف العربي وما يتخلله من فراغ ثم ضـرورة اتصالها معاً ، وهو مـا يزيد مـن تعقيد توليد خط مبني على أسس سليمهة سهلة التركيب ، فحرف الهاء مثلا

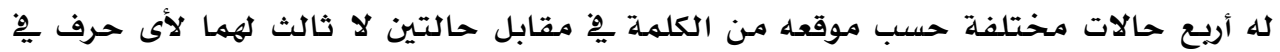
الللاتينية ، لذلك أصبح مـ الضـروري وضع معايير لتصميهم الخطوط العربية الرقهية تعالج تلك المشكلات ومن أهم هذه المعايير أولا الادتزام بالقواعد العامة وهس أسس تصميهم الحروف العريية ثم القواعد الخاصدة لتصميهم تلك الحروف وهي القواعد الخاصسة التي يحكمها الفهم الصحيح لأبعاد المشكل التصميهي كلأبجدية العربية ويأتي بعد ذلك ( ثانياً ) توجيه الخط من حيث كون تصهيه الأبجدية موجهة لموضوع سياسي أو اقتصسادي أو أطفال أو سيدات فلكلٍ المواصفات الخاصلة ثالثا مـراعاة العامل الصناعي والاقتصادي اختصسار أوجه الحروف - تقارب الصداعد والنازل - تطبيق

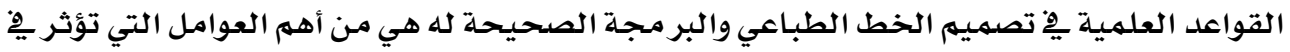
تصهيم الخط الطباعي ، يأتي بعد ذلك العامل الأخير والذي يتمثل يخ البرمجة الصحيحة كلأبجدية للحصول على أبجدية قابلة للتطبيق على كافة البر امـج ،

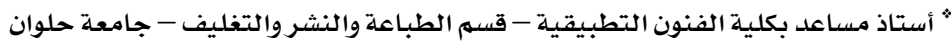

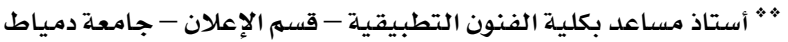

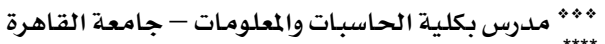

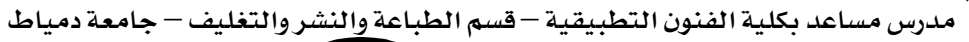




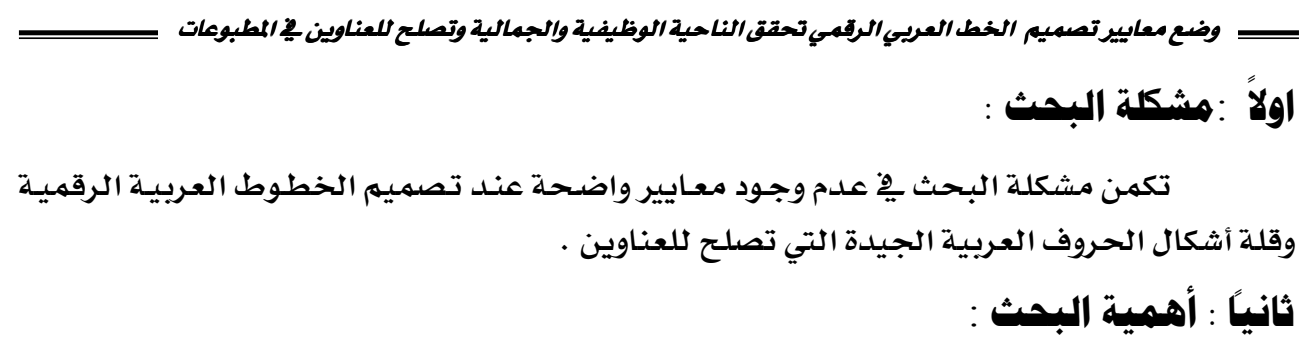

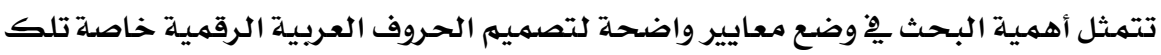

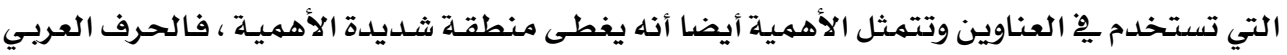

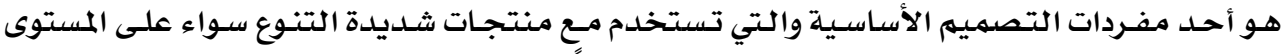

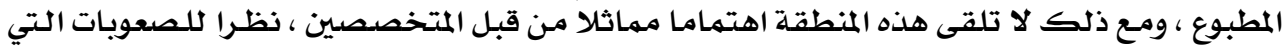

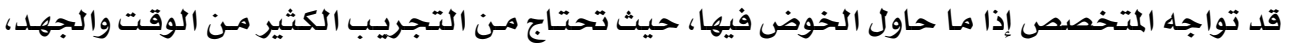

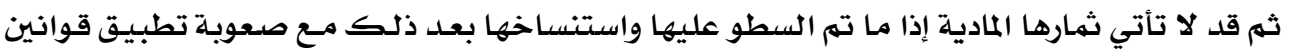

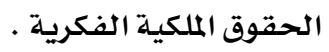

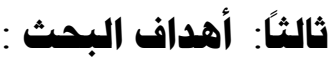

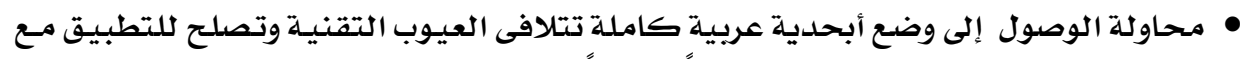

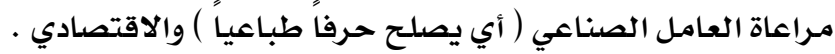

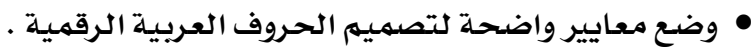

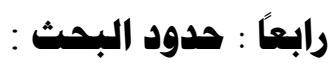

يستخدم البحث التقنيات المتاحة فى زمن إعداده .

خامساًا : منهمية البحث :

تعتمد الدراسة على المنهجين التاللين :

$$
\begin{aligned}
& \text { 1- المنهج الوصفى التحليلي . }
\end{aligned}
$$

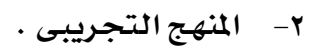

• استخدام برامـج تصميم الحروف الرقمية .

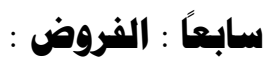

• يفترض البحث عندـ تطبيق معايير تصميهم أبجديـة رقميـة عربيـة ينتج خط طبـاعي خـال مـن

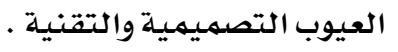




\section{كلمات دالة : nمات}

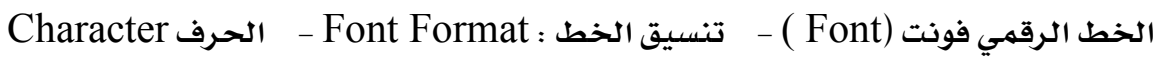

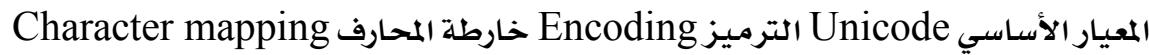

همبهـة

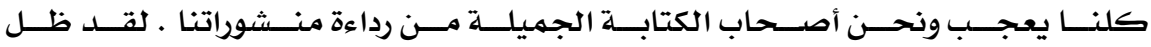

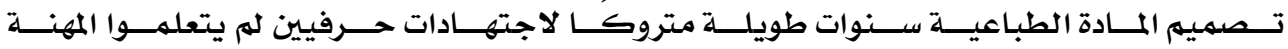

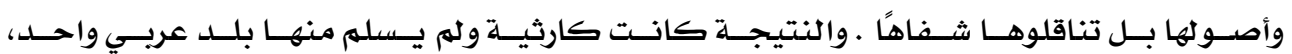

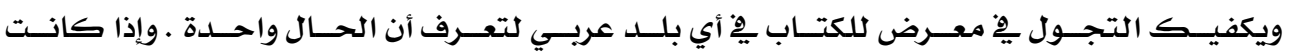

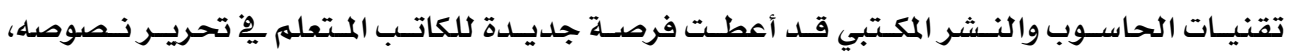

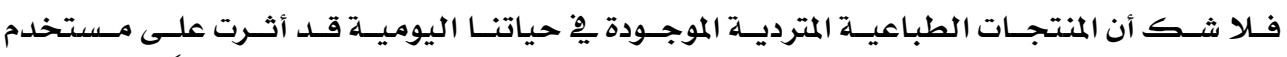

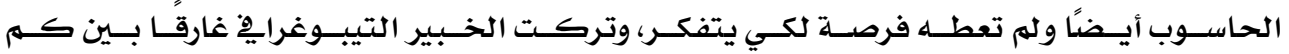

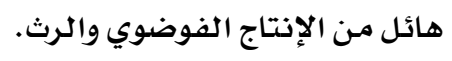

\section{معايير تصسيم الصروف العربية الطباعية}

بالنظر يِّ الخطوط العربية المتوفرة بكثرة ِِّ ساحة التيبوغرافيا، نجد أقل القليل من هذه

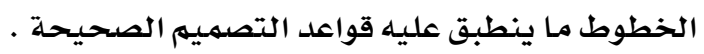
• أولا : يجب أن يخضع تصميم الخط لقواعد التصميم الصحيحة من حيث :

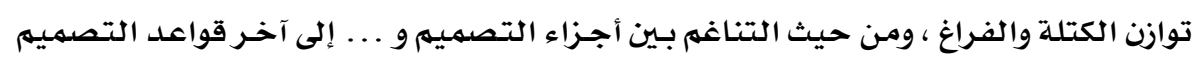

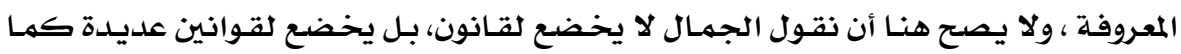

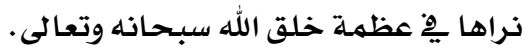

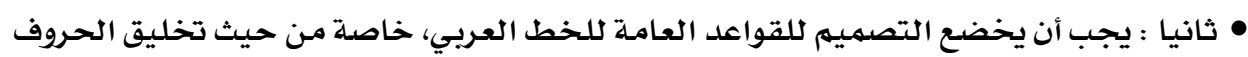

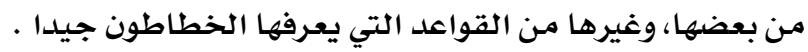

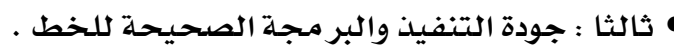

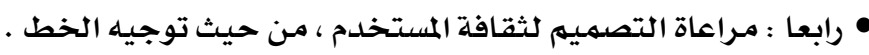

ويجب مراعاة عدة شروط عن تطوير شكل الحرف أهمها : مراهي

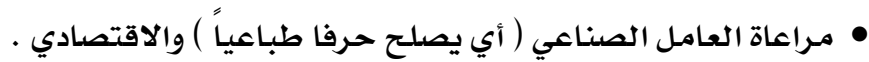

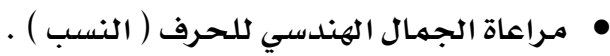

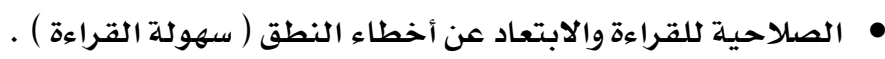

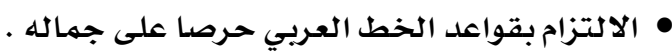


ومن هنـا يجب علينا أن نفتح البـاب لمزيـد مـن الجهود والتجـارب والمحاولات سعيًًا إلى تيسير

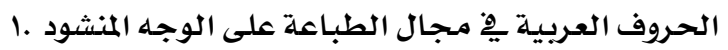

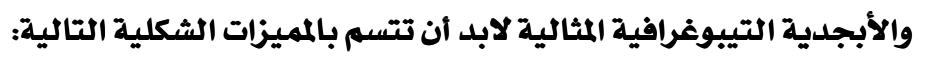

• البعد عن الأشكال الغير مألوفة ( لأن الأشكال غير المألوفة تقرأ ببطء لانهريزه ).

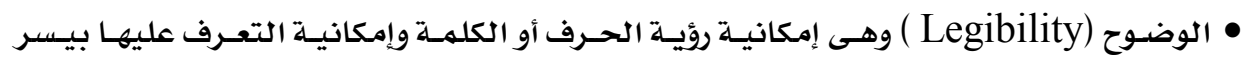

$$
\text { وسهولة . }
$$

• القدرة على القراءة (Readability ) وهى إمكانية الحصول على معنى الكلام بسهولة ومتابعة

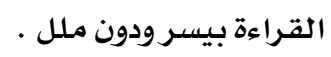

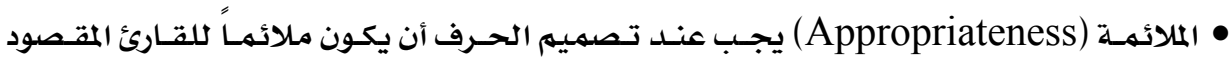

$$
\text { والرسالة التي سوف تكتب لها هذه الحروف بل ونوعية الورق التى سوف يطبع عليه. }
$$

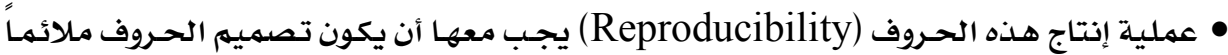

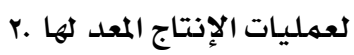

\section{وضع همايير لتصميميم خطوط العناوين :}
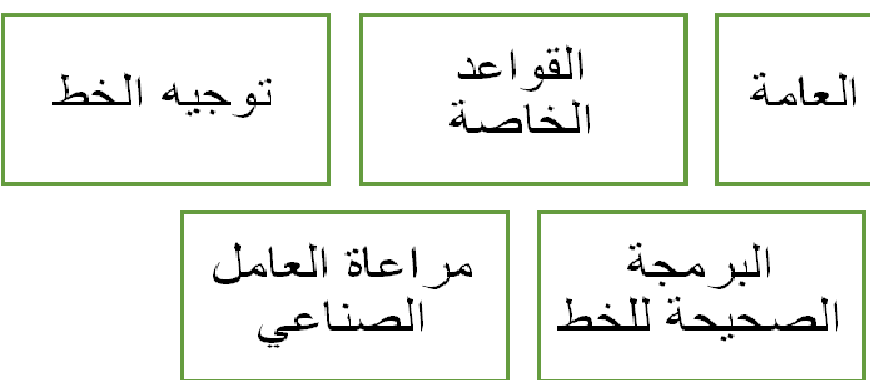

شكل رقم ( 1 ) معايير تصميم خطوط العناوين

أولاً القواعد العامة لتصميي خط العناوين :

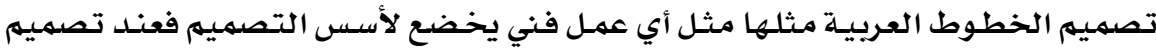

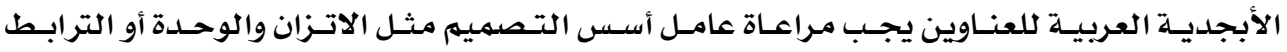

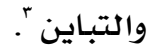

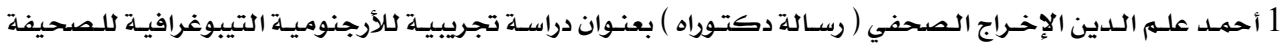

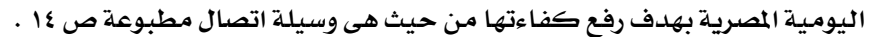

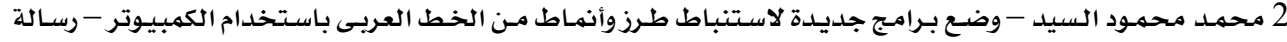

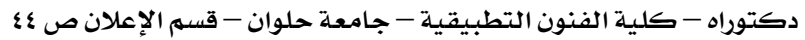

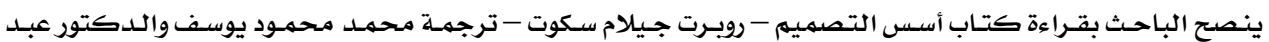

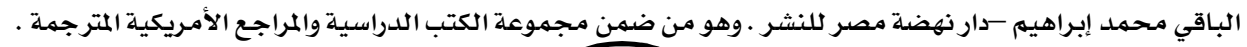


ثانياً القواعد الخاصة لتصميه خط العناوين :

القواعـد الخاصـة تحكمهـا الفهـم الصحيح لأبعـاد المشكل التصميهي للأبجديـة والقواعـد الخاصة منها علي سبيل المثال : • تعدد صور الحرف الواحد ِِ الخط العربي •

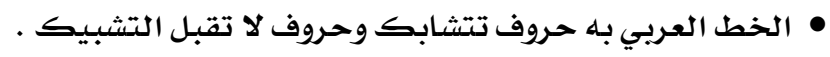

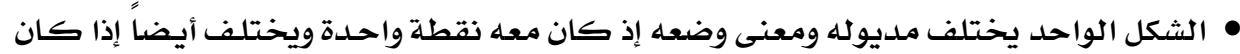

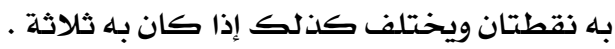

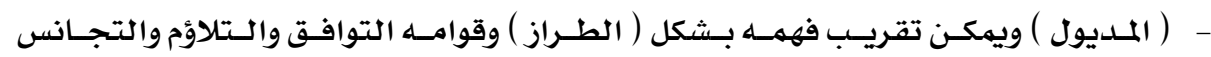

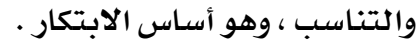

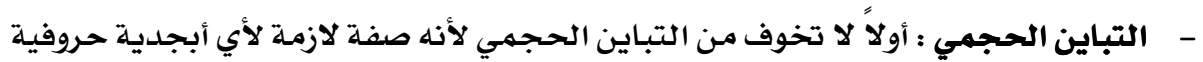

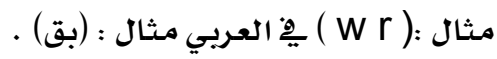
- الاختلاف الشكلي : يُسَهِّلْ التعريف والإدراك بسهولة مثال : ما سبق هي صفات خاصة تتسهم بها كل الخطوط العربية القديمة والحديثة .

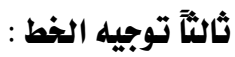

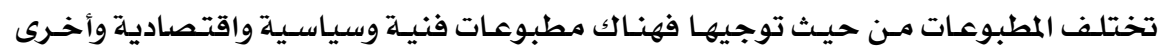

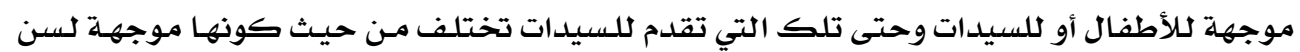

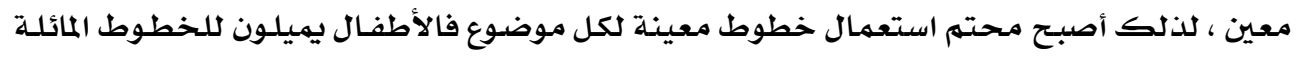

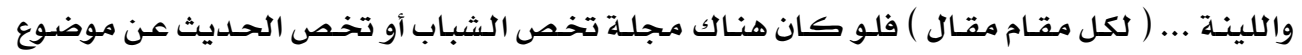

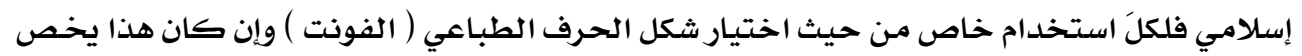

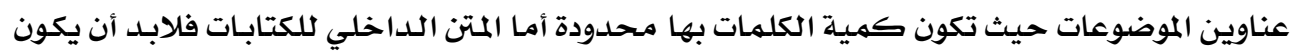

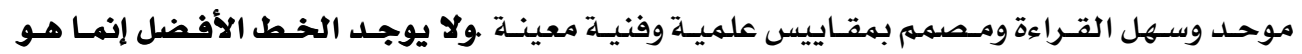

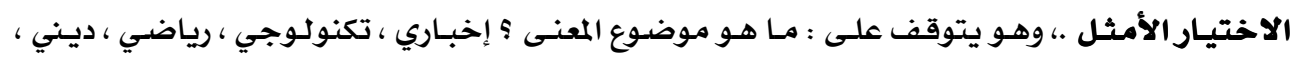

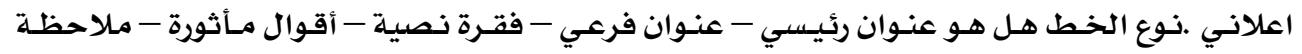

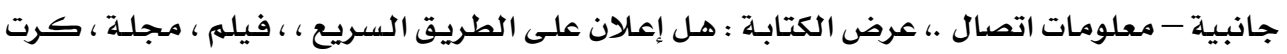

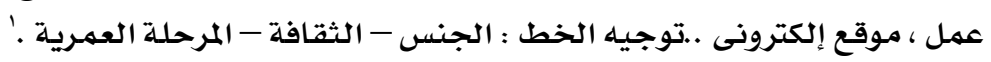

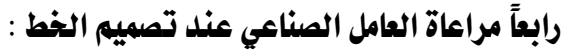

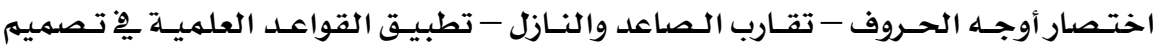

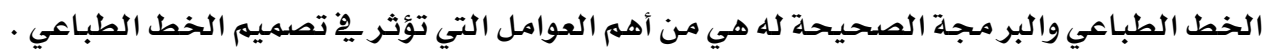

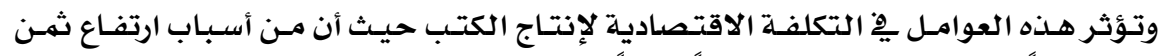

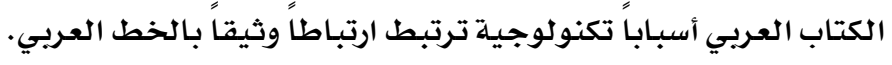

دليل استخدام الخط العربي يِّ الحاسوب - يوسف خريس WWw.yousefart.com 
تقليل صور الحرف الواحد . وأن تشغل كتل أجسـام الحروف مـن السطر أكبر قدر مستطاع

، وان تشغل منـه الزوائد أقل قدر مستطاع ·

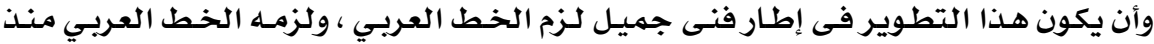

أكثر من اثنى عشر قرنا ، وليكن نصب أعينتا دائما أننا إذا قعدنا عن هذا التطوير فإنان الزحف الآلي ماض يخ سبيله ، وهو يلدخل على الخط العربي بين الحين والحين صور قميئة منفرة ، نضيق بها حينا

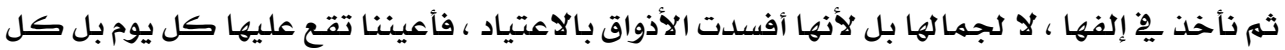
لحظة عددا مـن المرات يفوق كثيراً عدد المرات التي تقع فيها أعيننا على آثار فن الخط العربي الرفيع. وإذا تشبـث الموهوبـون مـن فنانينـا بـأهـاب المثل الفنيـة العليـا وحسدها ، أو رأوا الخـط العريسي

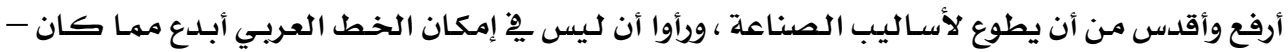

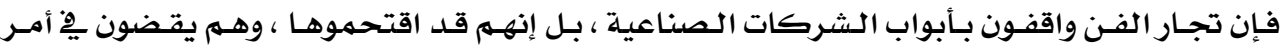

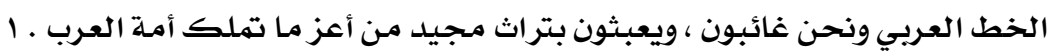

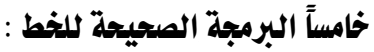

تعريــف الخـط الرقهـي ( الفونت ) Font : هـو عبـارة عـن مجهموعـة مـن الحــروف القابلـة

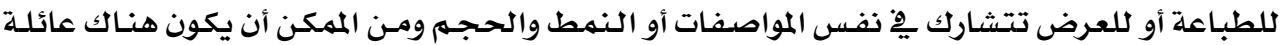
للخط الرقهـي مثل ( هلفاتيكا Helvetica ) وتكون لعائلـة الخط الرقهـي أكثر مـن خط " فونت "

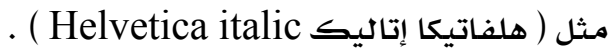

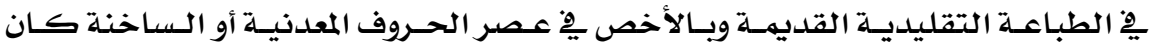

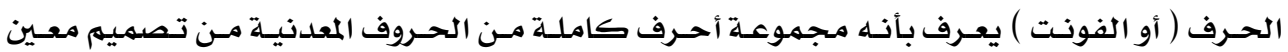
وكلها مـن نفـس الـوزن والأسـلوب والحجـهم ،، واليـوم يـشير الخـط ( الفونت ) إلى مـجموعـة أحسرف كاملة من نوع معين تصمهم يِّ شكل رقمي يحمل نفس الوزن والأسلوب ويختلف عن الحـروف المعدنيـة r.

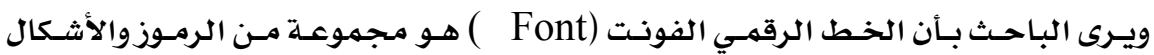
والأرقام صهمهت رقمياً مـن أجل الطباعة أو العرض صهمهت وفق قواعد عامـة وخاصـة .

\section{هطوات إنشاء النط الطباوي}

إنشاء الخوط الطباعية ( Typeface ) تحتاج إلى عدة خطوات لتحويل تصميم الخطوط الخاصـة بكل مصمهم وبرهجتها إلى خط طباعي هناك طريقتان وفيما يلى شـرح لكيفيـة إنشاء الخط 


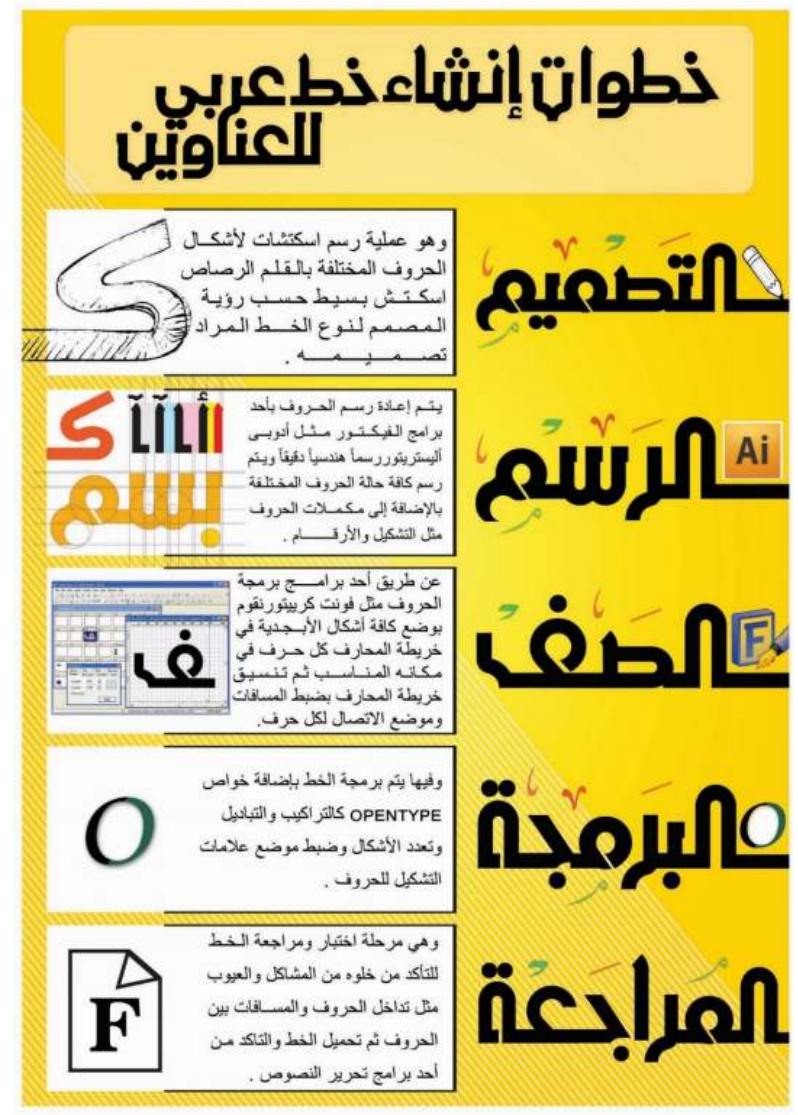

شكل رقم ( r ) خطوات انشاء خط طباعي

خطوات إنشاء الخط الطباتي :

أولاً مرحلة التصميه :

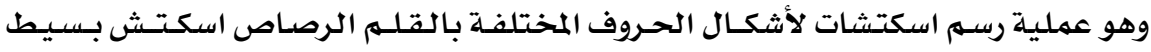

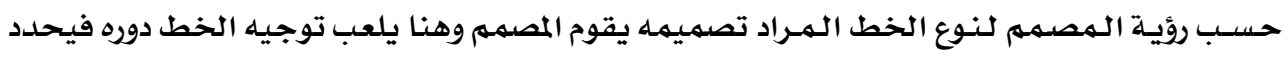

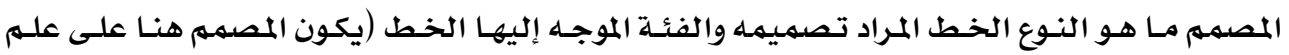

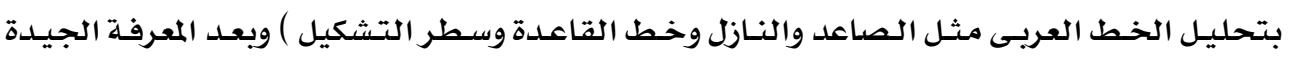

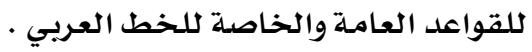

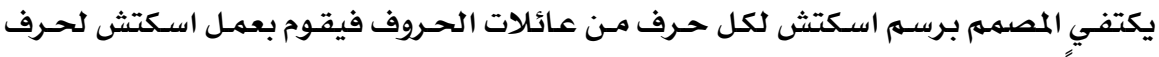

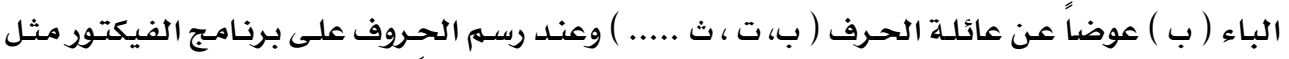

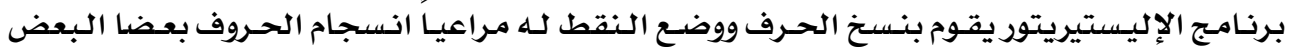

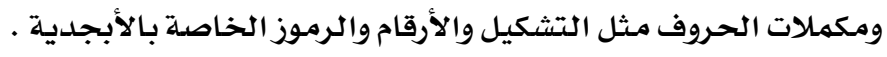




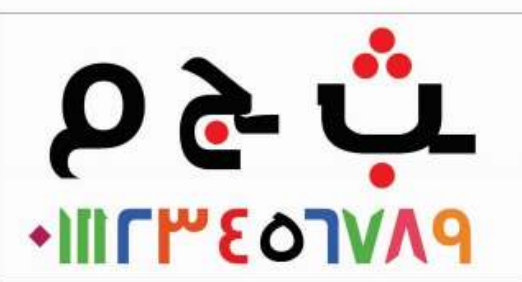

(شكل رقم ع نموذج لرسم الحروف )

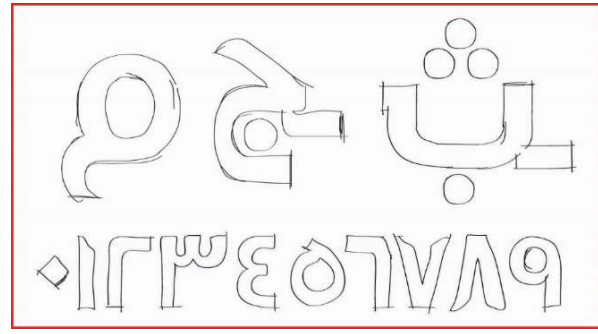

(شكل رقم r نموذج لاسكتشات سريعة لبعض الحروف ) ثانياً مرحلة الرسيم :

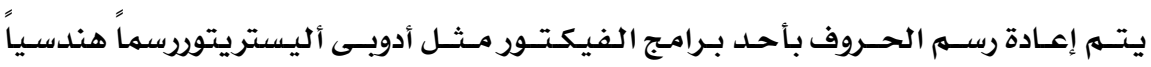
دقيقاً ويتم رسهم كافة حالة الحروف المختلفة ( حالة الحرف المفرد وحلته الوسطيه وحالته النهائيـة ووحلته أول الكلمة ) بالإضـافة إلى مـكمـلات الحروف مثل التشكيل والأرقــــام . هِّ هذه المرحلة يتم عمل خطوط إرشادية لارتفاع وانخفـاض كافة الحـروف وخط الأسـاس رويخ هذه المرحلة لابد من معرفة بعض المصطلحات الخاصلة بتحليل الحروف مثل :

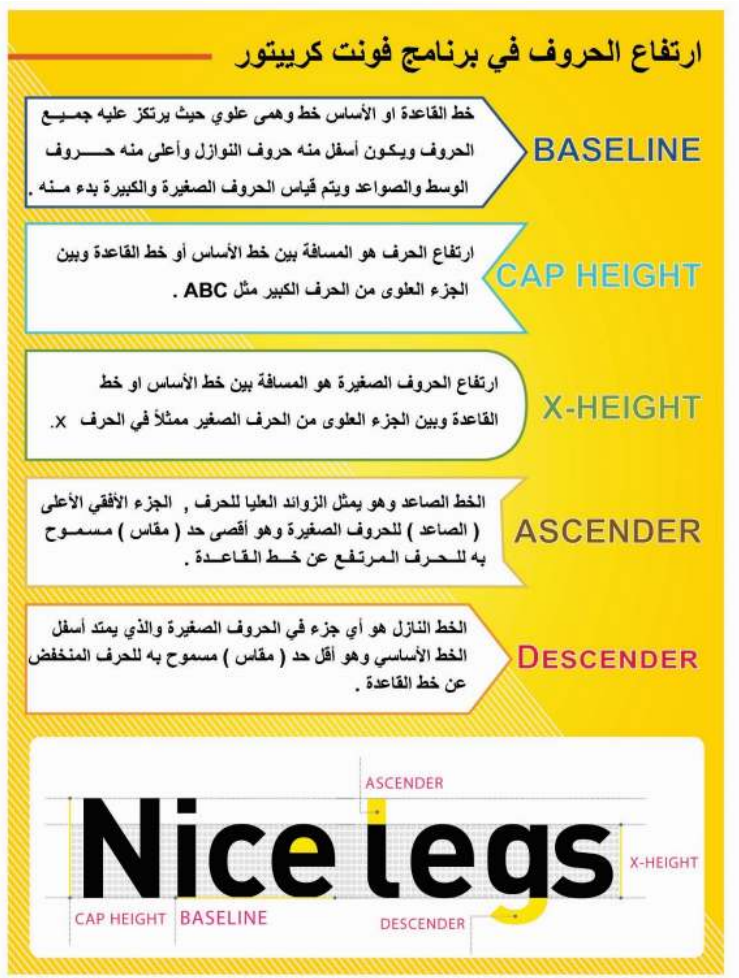

( شكل رقم r نموذج الحروف بِ برنامج فونت كرييتور ) 


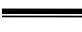

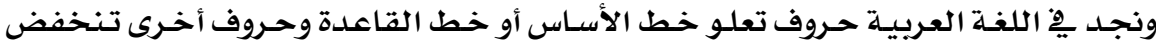

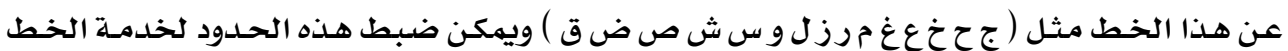

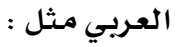

• نجعل الـ Baseline هو خط القاعدة لرسهم الحرف .

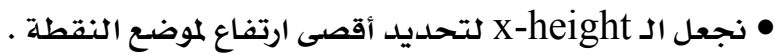

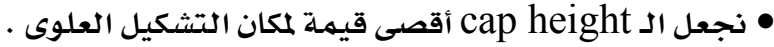

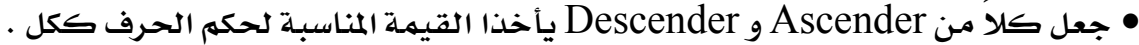

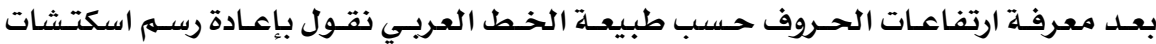

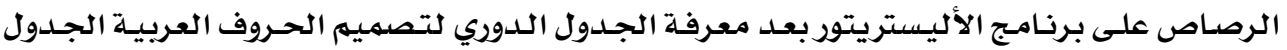

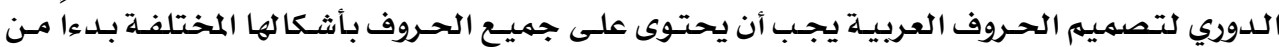

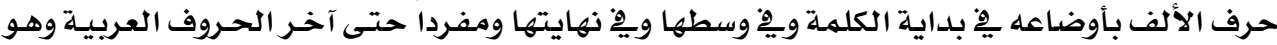

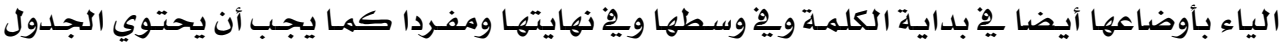

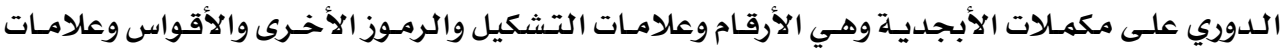

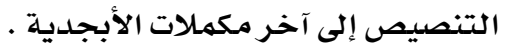

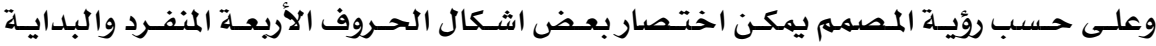

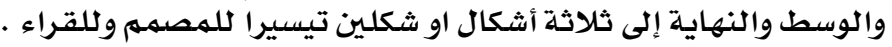

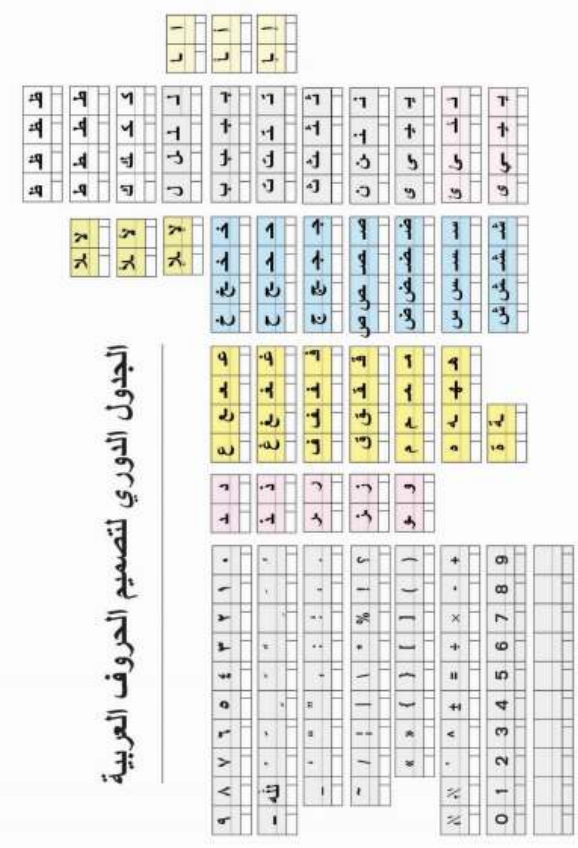

( شكل \& الجدول الدوري للحروف ) 


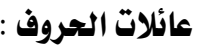

\begin{tabular}{|c|c|c|c|c|}
\hline عائلة الحرف & الحرف في النهاية & الحرف في الوسط & الحرف في البلداية & الحرف منفرد \\
\hline - & - & - & - & $s$ \\
\hline - & - & - & - & $\sim$ \\
\hline LL!!II & L & - & - & 1 \\
\hline- & - & - & - & ب \\
\hline- & - & - & - & $\tau$ \\
\hline- & - & - & - & 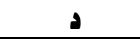 \\
\hline - & - & - & - & J \\
\hline- & - & - & - & س \\
\hline ض & سص & سم & صد & ص \\
\hline b & ط & h & ط & b \\
\hline$\dot{\varepsilon}$ & i- & - & غ & $\varepsilon$ \\
\hline ق & ق & قـ & ق & ف \\
\hline- & كـ & ك & 5 & ك \\
\hline- & لـ & $\perp$ & د & J \\
\hline- & $\leftarrow$ & $\leftarrow$ & مـ & $\hat{r}$ \\
\hline ب ت ث & - & i & ذـ & $\dot{j}$ \\
\hline- & L & + & $\Delta$ & 0 \\
\hline ؤسؤو & - & - & - & 9 \\
\hline- & - & - & - & ي \\
\hline- & ي & 䒠 & ئــ & s \\
\hline- & $\ddot{\alpha}$ & - & - & ة \\
\hline قتحة & & & & \\
\hline ضمة & & & & , \\
\hline سكوز & & & & \\
\hline كسره & & & & \\
\hline تنوين بالفتح & & & & $=$ \\
\hline تنوين بالكسر & & & & \\
\hline تنوين بالضم & & & & s. \\
\hline اشدة & & & & 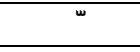 \\
\hline \multicolumn{5}{|c|}{ الأرقام } \\
\hline \multicolumn{5}{|c|}{ 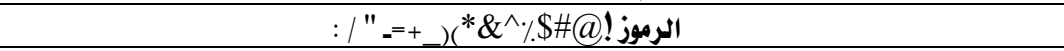 } \\
\hline \multicolumn{5}{|c|}{ ويتم تكرار الحروف التشابهة بواسطة برنامج الأليستريتور } \\
\hline
\end{tabular}

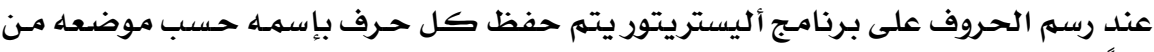

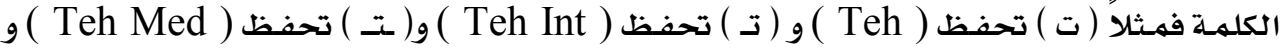

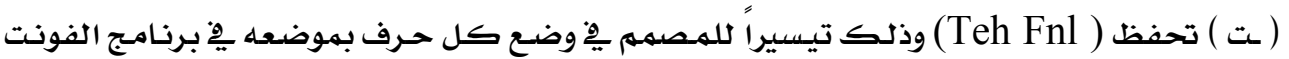
كرييتور 


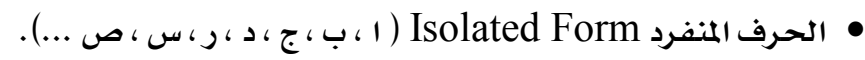

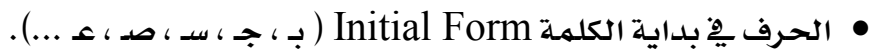

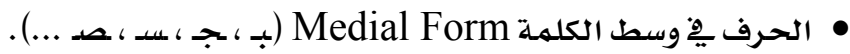

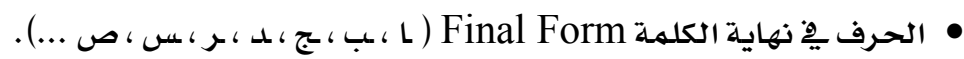

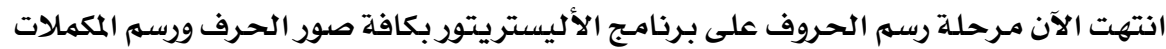

المرحلة الثالثة الصف والتنسيق :

وتأتي هذه المرحلة بعد مرحلة رسم الحروف ومكملاتها وضبطها وتحويلها من حروف خطية

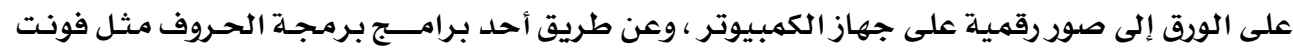

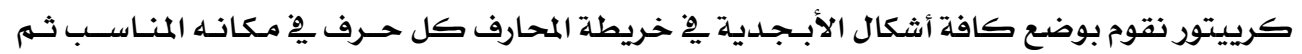

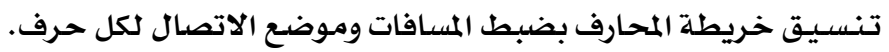

وعملية تنسيق وصف الحروف داخل برنامجج فونت كرييتور هناك طريقتان :

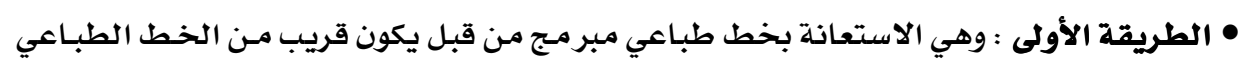

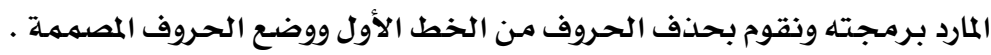

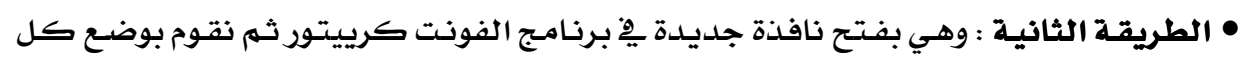

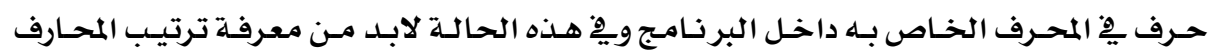

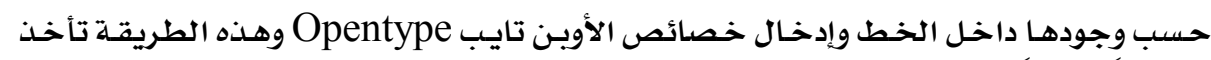

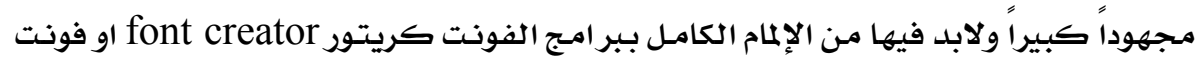

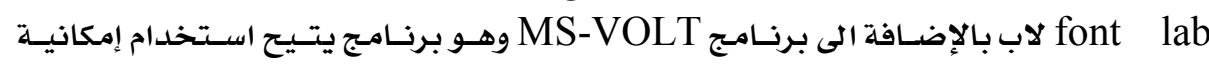

خصائص الأوبن تايب Opentype.

وتم إنثاء الخط باستخدام خط موجود مسبقاً وذلك عن طريق برنامج الفونت كرييتور: وفيما يلي نماذج لتطبيق خط عناوين تم تصميمـه من قبل الباحث :

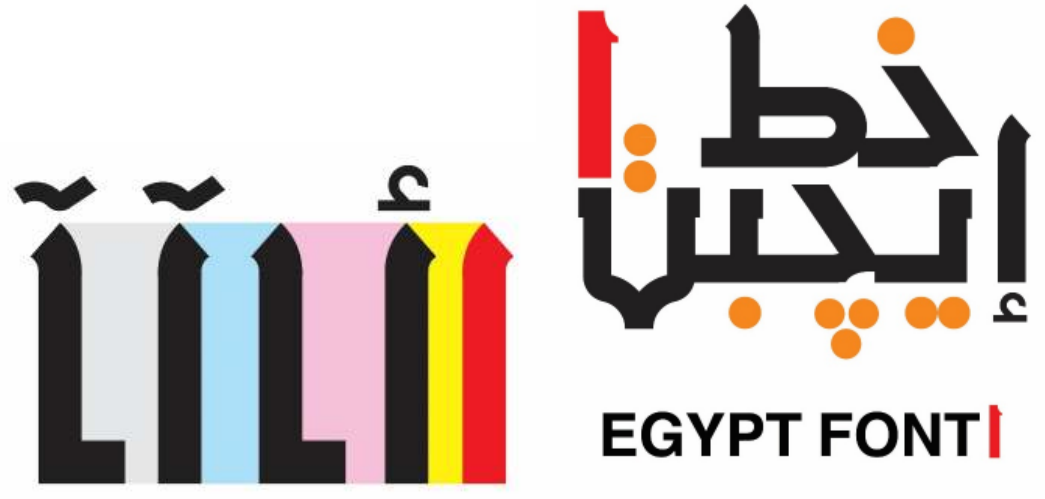




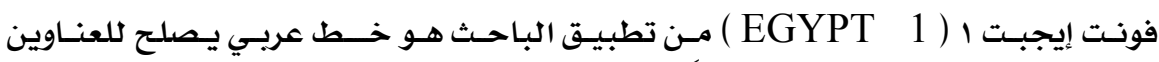

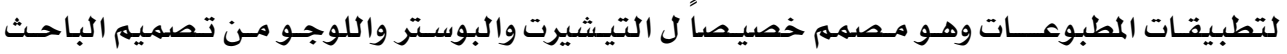

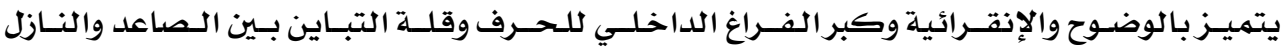

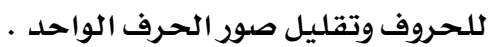

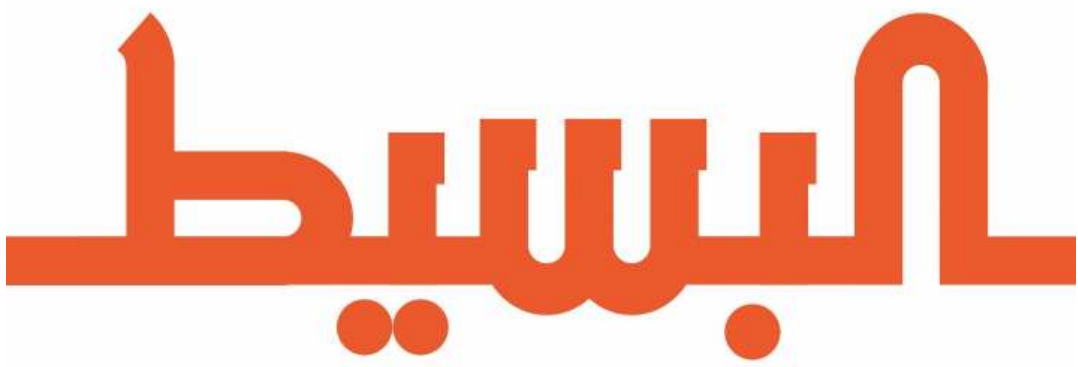

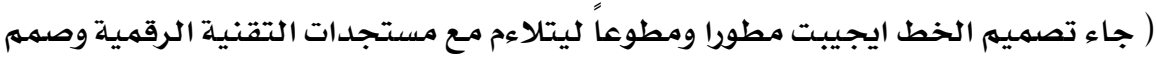

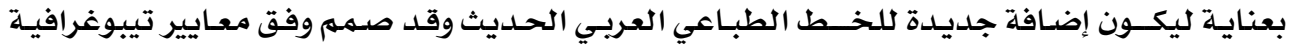
وبعد دراسات وتجارب على الشاشة والورق للحصول على حروف ذات مقروئية ووضـوح وبساطة وقوة ) . ل

فونت إيجبت ا ( EGYPT 1 ) عند تصميـمهـ روعي أن يكون مـرسوم على شبكة التصميم ويعتمدد على الدائرة والخط المستقيهم · 

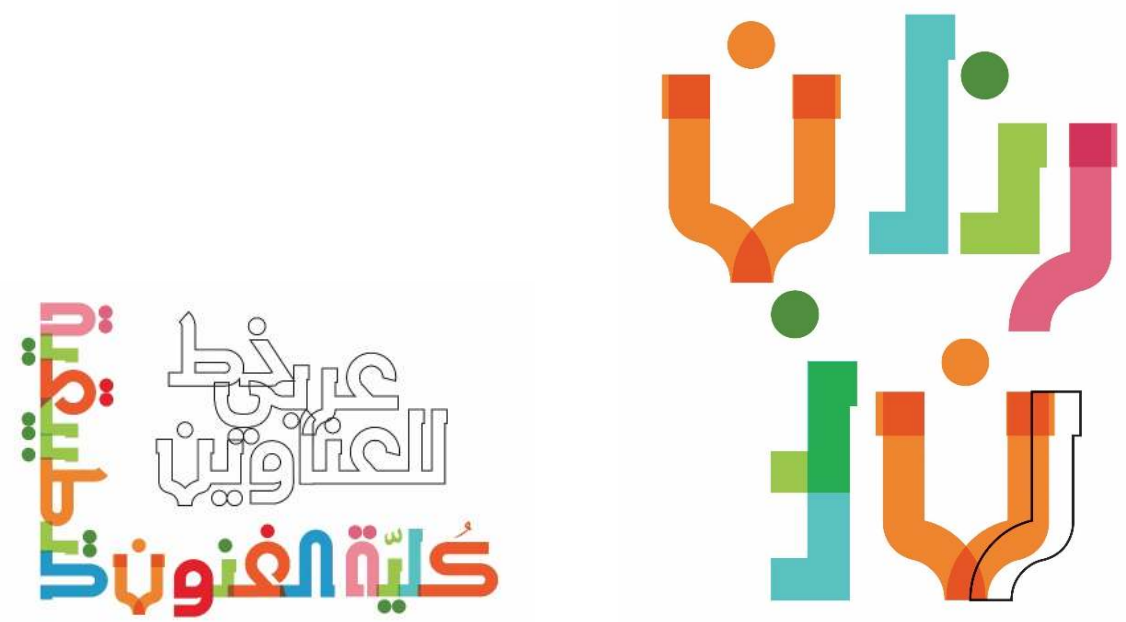

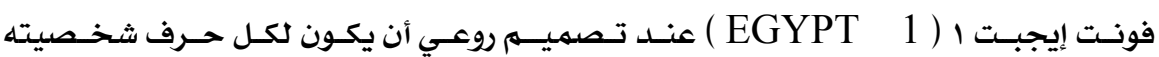

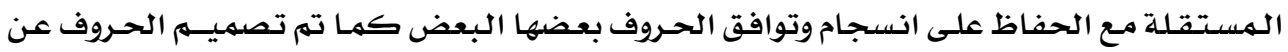

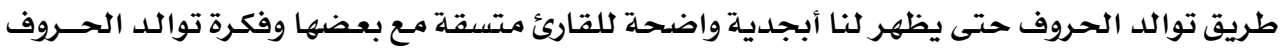

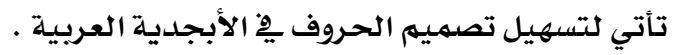

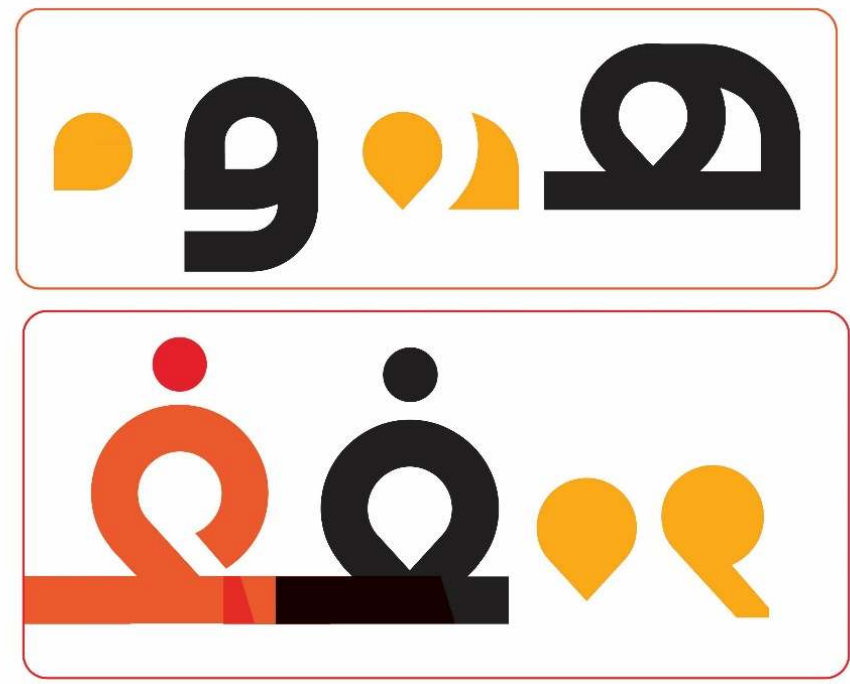

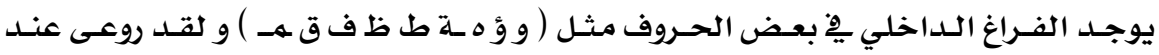

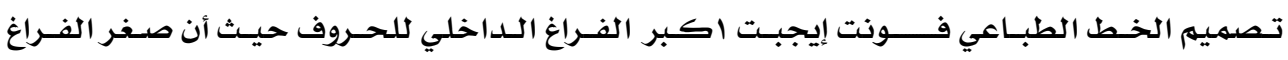

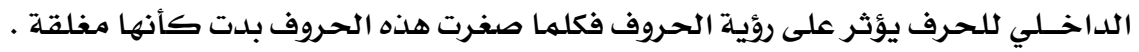




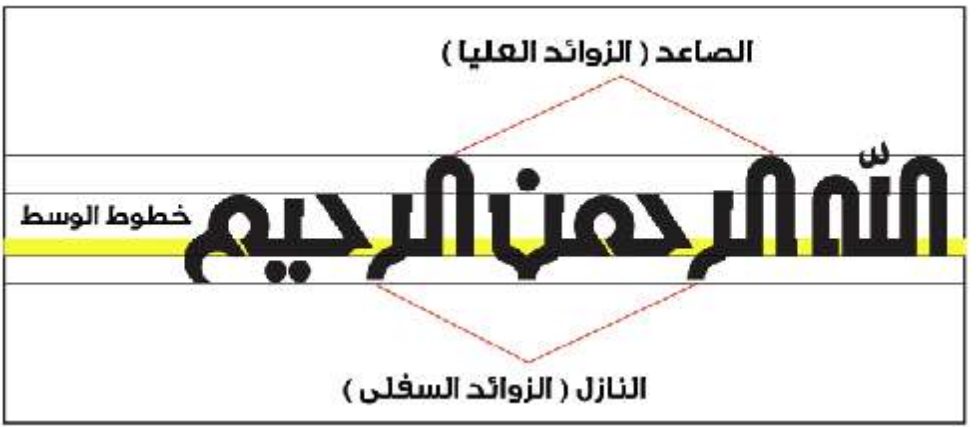

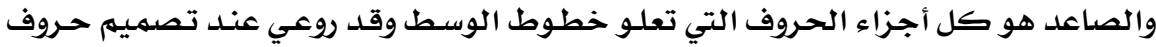

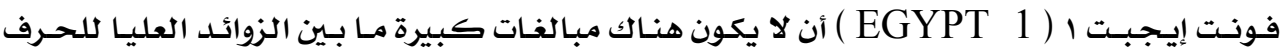

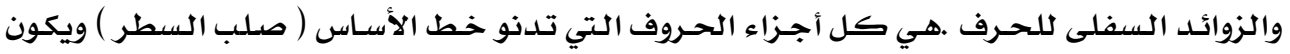

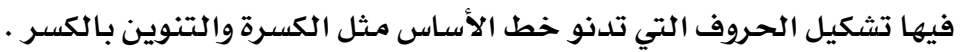
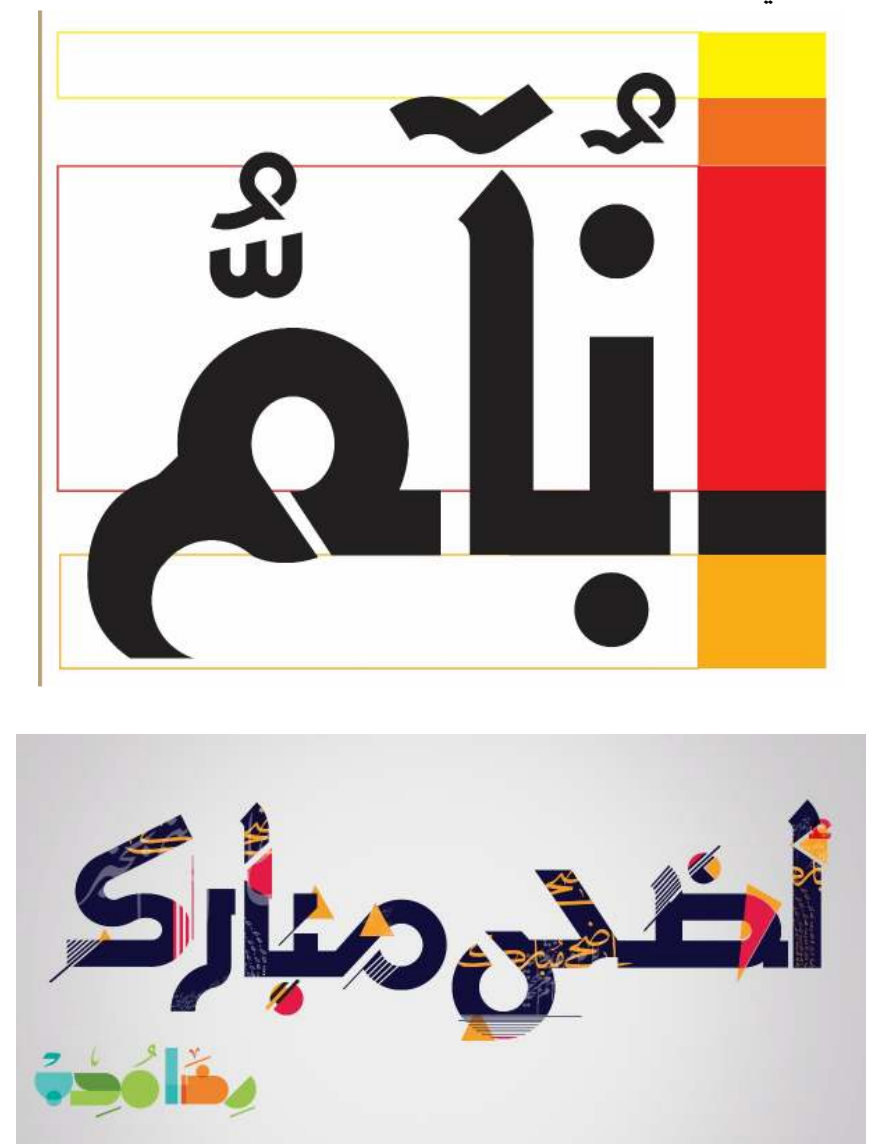
مجلة بحوث التريية النوعية - علد باء - أبريل r.lV

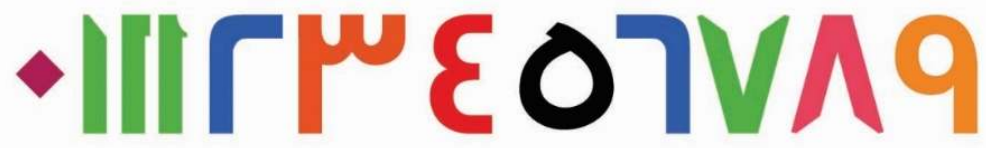

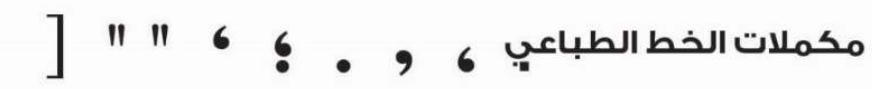

! $\mathbf{C}_{*} \cdot \operatorname{l}($ )

$\%=x \div-+$

$\bar{\omega} \boldsymbol{\omega} \Omega \Omega=$

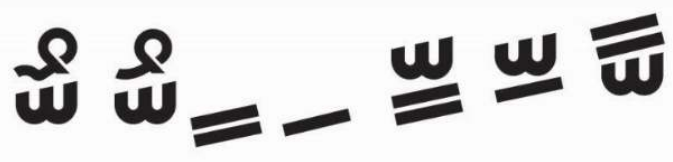

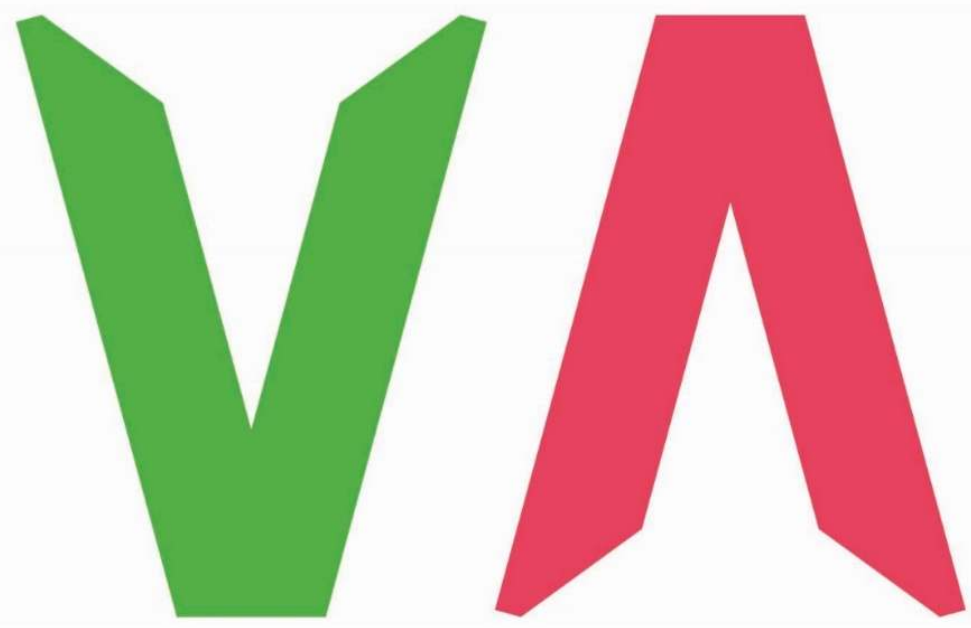




\section{المكملات الحيوية فى فونت إيجبت 1 ( EGYPT 1 )}

ـ المكملات لابد منها في تصميم الخط العربى وهى المصحح للنطق و أحكام

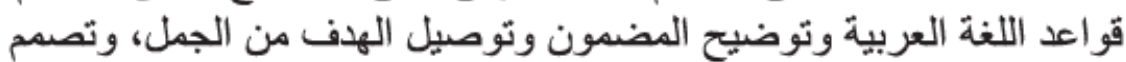

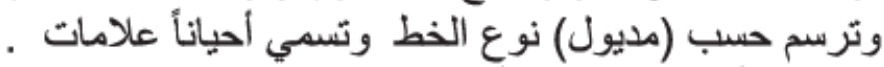

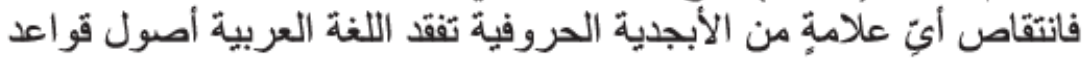

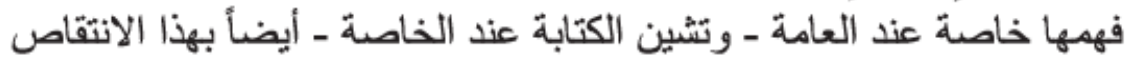

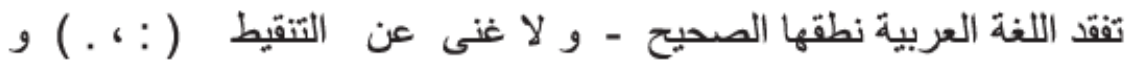

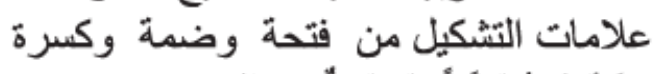

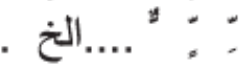

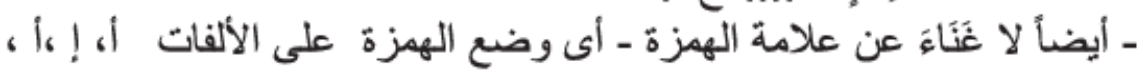

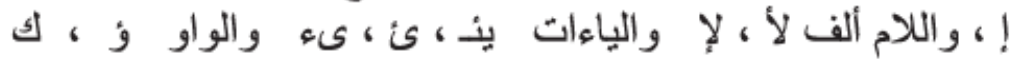

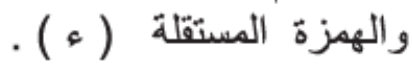

وفوق الواو المفردة مثل : ؤ، أو الياء مثل شىء، شيئاء، بطء ، همزة

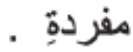
ـعلامة المد ( ) واستعملت علامة المد فى أربعة أوضاع في ألف المد أول

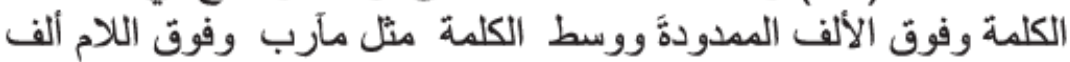

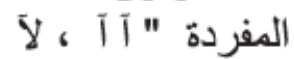

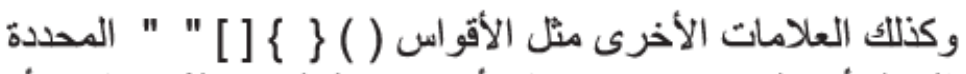

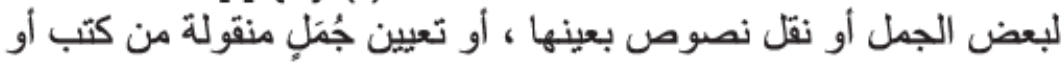

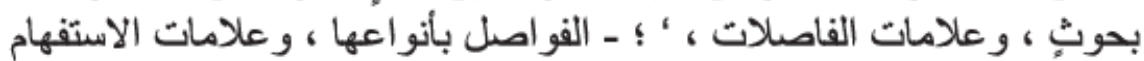

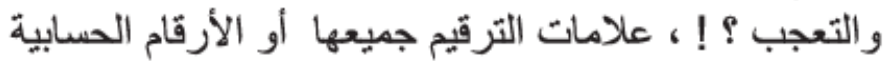

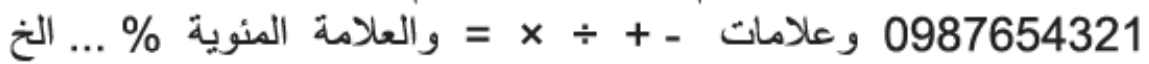

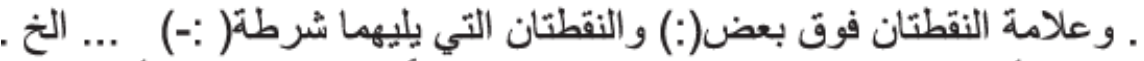

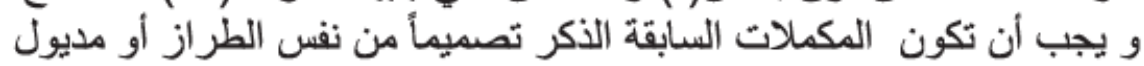

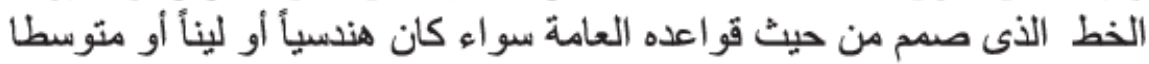

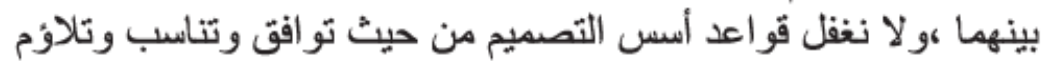
عناصر المكملات لنوع الخط اعلو المطلوب الخبم 


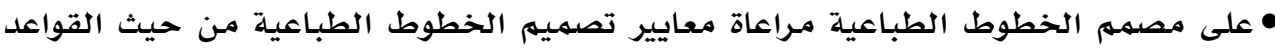

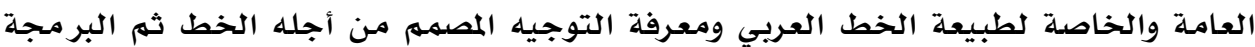

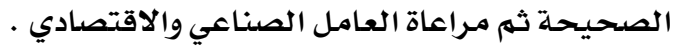

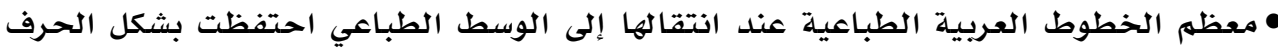

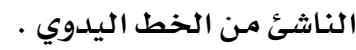

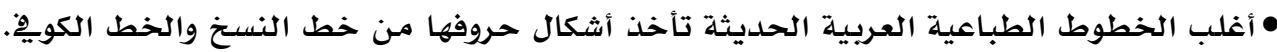

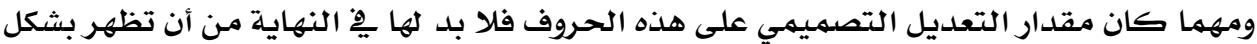

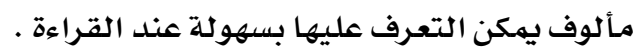

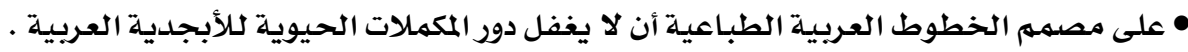

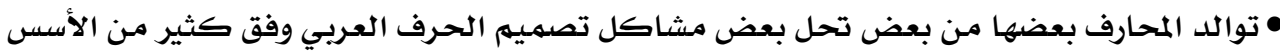

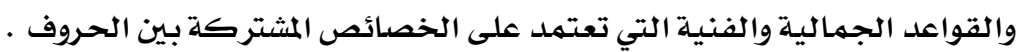

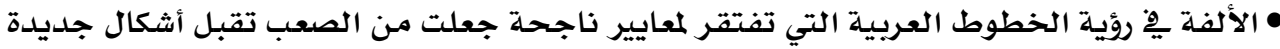

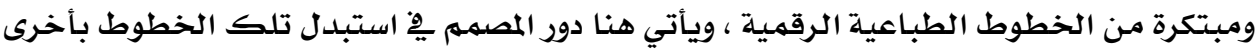

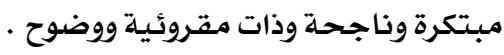

• تشجيع المؤسسات والهيئات على امتلاك الخط الخاص بها فهو جزء هام من الهوية البصرية للمؤسسـة . • تفعيل دور المراقبة وحقوق مصميمي الخطوط الطباعية .

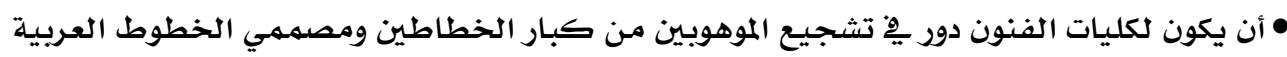

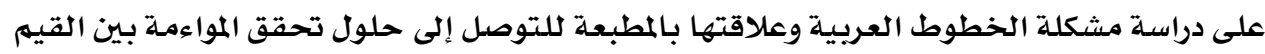

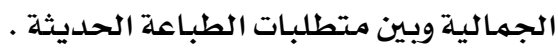

المراجع

1- الإخراج الصحفي ( رسالة دكتوراه ) بعنوان دراسة تجريبية للأرجنومية التيبوغرافية للصحيفة

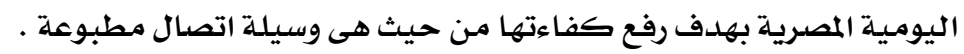

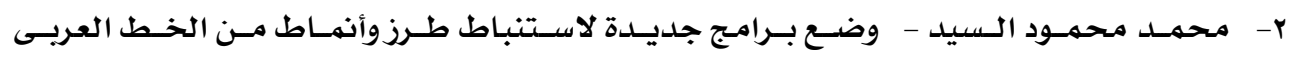

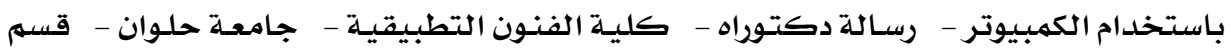

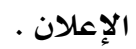

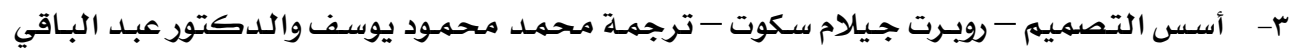

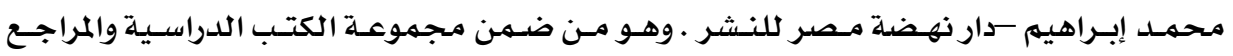

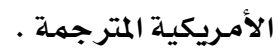




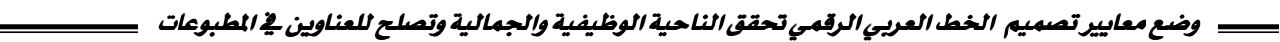
ع- دليل استخدام الخط العربي يِّ الحاسوب - يوسف خريس WWW.yousefart.com 0- حلقة بحث الخط العربى المجلس الأعلى لرعاية الفنون والآداب والعلوم الاجتماعية .

* http://whatis.techtarget.com/definition/font .

* John Wiley-Type Rules - the designer's guide to professional typography - Copyright C 2006. 


\section{Setting Standards for Digital Arabic Calligraphy to Achieve The Functional} and Aesthetic Aspects in Headlines Prints

\section{Abstract}

Over the last few years, several shapes of Arabic letters were introduced and used in printing field. While paper printing welcomed and used the new shapes without paying due attention to its suitability - given its variation and differences among those in charge - web pages of the big corporations refrained from using the new shapes and adopted only the familiar ones. Many of these new shapes did not achieve the quality and distinction as in the Latin letters for some reasons. The most important of all is the formation of the Arabic letter itself, whereas the letter shape depends on its location, and that its figure changes in accordance with the adjacent letters. There is also a big problem resulting from the great variation of the general structure or the boundaries surrounding the Arabic letter, the empty spaces inside it, and the necessity all of this together. Undoubtedly, this adds to the complexity of creating calligraphy based on correct basics that are easily composed. For example, the letter "Haa" has four cases depending on its location in the word, whereas all letters in Latin languages have only two cases. Therefore, in order to solve these problems, it is important to set criteria for the design of the digital Arabic calligraphy. Some of the most important criteria include:

- First: Adhering to the general rules, which are the basics of Arabic letters design, and then the special rules of these letters design, which rely on the proper comprehension of the dimensions of the Arabic alphabet shape design.

- Second: To direct calligraphy in such a way that the alphabet design corresponds to the subject; be it politics, economics, children or women. Every subject has its own specifications.

- Third: Considering the industrial and economic factor. This includes shortening the letter directions, closeness of ascending and descending movements, applying scientific rules to the design of printing calligraphy and its right programming. These are the most important factors that affect the printing calligraphy design.

- Finally: The right programming of alphabet, to be able to use it with all programs. 